\title{
Preparation and Characterization of SBA-15 Supported Cobalt- Molybdenum Sulfide Catalysts for HDS Reaction: An All Sulfide Route to Hydrodesulfurization Catalysts
}

\author{
Z.-D. Huang - W. Bensch · L. Kienle - S. Fuentes • \\ G. Alonso - C. Ornelas
}

Received: 18 March 2008/ Accepted: 3 May 2008/Published online: 28 May 2008

(C) Springer Science+Business Media, LLC 2008

\begin{abstract}
MoS}_{2}$ hydrodesulfurization (HDS) catalysts promoted with Co supported on SBA-15 were synthesized from sulfur-containing Mo sources [ammonium thiomolybdate (ATM), and tetramethylammonium thiomolybdate (TMATM)] and Co complexes cobalt dimethylthiocarbamate by using different synthesis strategies in order to achieve active catalysts. The (Co)- $\mathrm{MoS}_{2} / \mathrm{SBA}-15$ catalysts were characterized with $\mathrm{X}$-ray diffraction, $\mathrm{N}_{2}$-physisorption and High-Resolution Transmission Electron Microscopy. The catalytic performance in the HDS reaction of dibenzothiophene was examined at $T=623 \mathrm{~K}$ and $P_{\mathrm{H} 2}=3.4 \mathrm{MPa}$. The results of the experiments suggest that the sequence of impregnation steps has no significant influence on the HDS activity. On the other hand, the use of different thiomolybdate precursors significantly affects the catalytic activity. The catalysts derived from TMATM show lower HDS activities compared to the catalysts synthesized from ATM which is probably due to the presence of pronounced pore blocking as well as the generation of big needle-like aggregates of the $\mathrm{Co}-\mathrm{MoS}_{2}$ phase. It seems
\end{abstract}

Z.-D. Huang · W. Bensch $(\bowtie)$

Institut für Anorganische Chemie, University of Kiel,

Olshausenstraße 40-60, 24098 Kiel, Germany

e-mail:wbensch@ac.uni-kiel.de

L. Kienle

Max-Planck-Institut für Festkörperforschung, Heisenbergstr. 1,

70506 Stuttgart, Germany

S. Fuentes

Centro de Ciencias de la Materia Condensada, UNAM,

Ensenada, Baja California C.P.22860, Mexico

G. Alonso · C. Ornelas

Centro de Investigación en Materiales Avanzados S. C.,

Chihuahua, Chihuahua C.P. 31109, Mexico that the formation of intermediate $\mathrm{MoS}_{3}$ is not a prerequisite for the generation of catalytic active CoMoS phases. The high activity and high selectivity for the direct desulfurization pathway of catalysts prepared with ATM despite the large $\mathrm{MoS}_{2}$ stacking could be due to the generation of a large number of coordinately unsaturated sites.

Keywords Hydrodesulfurization - Methylammonium thiomolybdate Cobalt dimethyldithiocarbamate . $\mathrm{Co}-\mathrm{MoS}_{2} / \mathrm{SBA}-15$ catalysts $\cdot$ HRTEM $\cdot$ CUS . SBA-15 support $\cdot \mathrm{MoS}_{2}$ morphology

\section{Introduction}

Environmental regulation requires lower content of sulfur in diesel engine fuel to $50 \mathrm{ppm}$ by the year 2005 and the sulfur content will be probably reduced even further in the near feature. This worldwide environmental pressure on fuel manufacturing has awoken a renewed interest in the preparation of more efficient hydrotreating catalysts. Various preparation methods have been applied to obtain hydrotreating catalysts including comaceration [1], homogenous sulfide precipitation [2] and thiosalt decomposition [3]. Traditionally, hydrodesulfurization (HDS) catalysts contain Mo or W sulfides supported on alumina and promoted with Co or Ni. Recently, mesoporous SBA15 has been studied as catalyst support material due to the larger pores, thicker pore walls and higher hydrothermal stability compared to other silica molecular sieves such as HMS or MCM-41 [4]. Indeed, Vradman et al. demonstrated the excellent potential of high loading Ni-W/SBA15 catalysts for deep hydrotreatment of petroleum feedstocks [5]. These catalysts were prepared by ultrasonication deposition of $\mathrm{WS}_{2}$. SBA-15 supported Mo, CoMo and 
NiMo catalysts was also found by Rao et al. to present higher HDS activity compared to alumina supported catalysts prepared in a similar manner [6]. Further, SBA-15 can be easily modified with various hetero-atoms like $\mathrm{Al}, \mathrm{Ti}$ and Zr. It was reported by Klimova et al., Rao et al. and Fierro et al. that modified SBA-15 supports exhibit stronger metal-support interactions with respect to pure SBA-15 yielding a high dispersion of the deposited $\mathrm{Ni}(\mathrm{Co})$ and $\mathrm{Mo}$ active species and consequently greater activity in the HDS [7-10]. In the majority of cases these catalysts were prepared via an oxide route, i.e., SBA-15 was impregnated with transition metal salts like ammonium heptamolybdate, nickel (cobalt) nitrate or nickel (cobalt) acetate and these materials were the calcined to produce stable oxides. Finally, the oxide catalysts were then activated either prior to (ex situ) or during the start-up (in situ) of the hydrotreatment process. However, the calcination step can cause a loss of active metals on the support and a complete sulfidation of the active phase is difficult to achieve [11]. Recently, we reported the synthesis and catalytic performance of SBA-15 supported Co-Mo sulfide catalysts derived from ammonium thiomolybdate (ATM) [12]. The catalysts activated by a gas mixture $\mathrm{H}_{2} / \mathrm{N}_{2}\left(\mathrm{H}_{2}=10 \%\right)$ showed a higher HDS activity compared to a commercial $\mathrm{CoMo} / \gamma-\mathrm{Al}_{2} \mathrm{O}_{3}$ material, despite the pronounced $\mathrm{MoS}_{2}$ stacking and the presence of long $\mathrm{MoS}_{2}$ slabs. Cobalt acetate has been applied as the Co source and the precursor was sulfided in a $\mathrm{H}_{2} \mathrm{~S}$ atmosphere to form $\mathrm{CoS}_{x} / \mathrm{SBA}-15$ prior to the impregnation with the Mo compound. Moreover, the cobalt sulfide $\mathrm{Co}_{9} \mathrm{~S}_{8}$ was easily detected by X-ray powder diffractometry. In the literature [13-15] it has been reported that the sequence of the formation of the metal sulfides has an important effect onto the development of HDS catalysts. Complexation of $\mathrm{Co}$ and $\mathrm{Ni}$ with a chelating agent retards the sulfidation of $\mathrm{Co}$ and $\mathrm{Ni}$ promoters beyond the sulfidation of the Mo species, leading to efficient promotion of the $\mathrm{MoS}_{2}$ phase and a reduced formation of bulk Co or Ni sulfides. These observations encouraged us to apply a cobalt complex (cobalt dimethylthiocarbamate, CoDMTC) as a precursor instead of Co acetate or Co nitrate for the synthesis of Co promoted $\mathrm{MoS}_{2}$ catalysts hoping that the generation of less active binary Co sulfide phases will be inhibited by this new approach.

The objectives of the present work are to explore the HDS activity of Co-Mo catalysts supported on mesoporous SBA-15, which were synthesized from $\mathrm{S}$ containing Mo sources ATM (TMATM) and the $\mathrm{S}$ containing Co complex CoDMTC. The synthesis strategy presented here allows the decomposition of the precursor materials in a $\mathrm{H}_{2} / \mathrm{N}_{2}\left(\mathrm{H}_{2}\right.$ $10 \%$ ) gas flow avoiding the usage of toxic $\mathrm{H}_{2} \mathrm{~S}$. In general, consecutive impregnation of the support with Co and Mo sources was carried out whereas first CoDMTC was applied followed by the Mo source. Experiments were also performed with impregnation of the material with CoDMTC after the formation of (Co)Mo sulfides on SBA-15. The different syntheses should allow monitoring the influence of the impregnation order onto the HDS activity of the materials. The supported catalysts were characterized by X-ray diffractometry (XRD), nitrogen physisorption using the Brunauer, Emmett and Teller method (BET) and HighResolution Transmission Electron Microscopy (HRTEM).

\section{Experimental Section}

\subsection{Sample Preparation}

\subsubsection{Synthesis of Pristine Mesoporous SBA-15}

Eight grams of poly(ethyleneglycol)-block-poly(propyleneglycol)-block-poly(ethyleneglycol) triblock copolymer (Aldrich, pluronic, P-123) was dissolved in $240 \mathrm{~g}$ of water and $28.6 \mathrm{~g}$ of concentrated hydrochloric acid at $303 \mathrm{~K}$ on a water bath. After drop wise addition of $16 \mathrm{~g}$ of tetraethylorthosilicate, the reaction mixture was stirred for $24 \mathrm{~h}$ at $303 \mathrm{~K}$. The resulting gel was transferred into a Teflon bottle and heated to $353 \mathrm{~K}$ to obtain SBA-15 with $6 \mathrm{~nm}$ pores. The resulting white powder was filtered and washed with deionized water, and the surfactant was removed by Soxhlet extraction at $351 \mathrm{~K}$ with a mixture of $970 \mathrm{~mL}$ of ethanol and $30 \mathrm{~mL}$ of concentrated hydrochloric acid. After washing with ethanol, the white powder was dried at room temperature under vacuum for about 1 week.

\subsubsection{Synthesis of $\mathrm{Co}-\mathrm{MoS}_{2} / \mathrm{SBA}-15$}

Typically, $2 \mathrm{~g}$ of SBA-15 was stirred for $4 \mathrm{~h}$ in $100 \mathrm{~mL}$ of a saturated CoDMTC chloroform solution. Afterwards, the solid was obtained by filtration and the product CoDMTC/ SBA-15 was dried under vacuum over night. The precursor material CoDMTC/SBA-15 was stirred in $150 \mathrm{~mL}$ of saturated aqueous solutions of ATM at $298 \mathrm{~K}$ or (TMATM at $328 \mathrm{~K}$ ). After $4 \mathrm{~h}$ of stirring the products were filtered without washing and then they were activated at $773 \mathrm{~K}$ for $3 \mathrm{~h}$ under a $\mathrm{H}_{2} / \mathrm{N}_{2}\left(\mathrm{H}_{2}, 10 \%\right)$ gas flow at atmospheric pressure. The impregnation/activation cycle was carried out twice to prepare $\mathrm{Co}-\mathrm{MoS}_{2} / \mathrm{SBA}-15$ catalysts with higher Co and Mo loading. Catalysts are named according to their metal loading and type of precursors employed as, e.g., $\mathrm{Co}(\mathrm{X}) \mathrm{Mo}(\mathrm{Y}) / \mathrm{SBA}-15(\mathrm{~A})(\mathrm{X}$ is wt $\% \mathrm{Co}$ and $\mathrm{Y}$ is wt $\%$ Mo loading, respectively, and A means catalysts prepared from ATM). $\mathrm{Co}(\mathrm{X}) \mathrm{Mo}(\mathrm{Y}) / \mathrm{SBA}-15(\mathrm{~B})$ (B means catalysts synthesized from TMATM).

Two additional samples were prepared through postimpregnation with CoDMTC. The first one was prepared to 
enhance the Co concentration of $\mathrm{Co}-\mathrm{MoS}_{2} / \mathrm{SBA}-15$. Co$\mathrm{MoS}_{2} / \mathrm{SBA}-15$ which has been prepared in the above described way using ATM as precursor was treated with $100 \mathrm{~mL}$ of a saturated CoDMTC chloroform solution and the product was then activated under the above mentioned conditions. The second catalyst was prepared as follows: $2 \mathrm{~g} \mathrm{SBA}-15$ was stirred in $150 \mathrm{~mL}$ of saturated aqueous solution of ATM at $298 \mathrm{~K}$. After filtration, the catalyst was calcined at $773 \mathrm{~K}$ for $3 \mathrm{~h}$ in a $\mathrm{H}_{2} / \mathrm{N}_{2}\left(\mathrm{H}_{2}, 10 \%\right)$ gas flow at atmospheric pressure. The $\mathrm{MoS}_{2} / \mathrm{SBA}-15$ was treated with a saturated chloroform solution of CoDMTC. After filtration the catalyst was activated applying the above mentioned conditions. These two catalysts are denoted as $\mathrm{Co}(\mathrm{X}) \mathrm{Mo}(\mathrm{Y}) / \mathrm{SBA}-15(\mathrm{C})$.

For comparative purposes, two unsupported catalysts were prepared as follows: mixtures of the ATM (TMATM) and CoDMTC were manually ground in an agate mortar and $\mathrm{Co} / \mathrm{Mo}$ ratios were kept at 0.2 . The products were then decomposed in a $\mathrm{H}_{2} / \mathrm{N}_{2}\left(\mathrm{H}_{2}, 10 \%\right)$ atmosphere at $773 \mathrm{~K}$ for $3 \mathrm{~h}$. These two catalysts are designed as $\mathrm{CoMo}(\mathrm{ATM})$ and CoMo(TMATM).

The precursors ATM and TMATM were synthesized using the method reported previously [16] and the preparation of CoDMTC has been reported by Cambi et al. [17].

\subsection{Sample Characterization}

X-ray diffraction patterns were measured on a Siemens D5000 diffractometer at room temperature using $\mathrm{CuK} \alpha$ radiation $(\lambda=0.154056 \mathrm{~nm})$. Nitrogen adsorption measurements were carried out at $77 \mathrm{~K}$ on a Quantachrom Autosorb-1. Samples were degassed under flowing argon at $473 \mathrm{~K}$ for $2 \mathrm{~h}$ before $\mathrm{N}_{2}$ adsorption. The BET surface areas were calculated from $p / p_{0}=0.03-0.3$ in the adsorption branch. The chemical composition of the catalysts (in wt\%, average of five measurements at different points of the sample) was determined with energy dispersive X-ray spectroscopy (EDS) analysis with a Philips ESEM XL 30 microscope.

High-Resolution Transmission Electron Microscopy and SAED were performed with a Philips CM 30ST microscope $\left(300 \mathrm{kV}, \mathrm{LaB}_{6}\right.$ cathode, $\left.C_{\mathrm{S}}=1.15 \mathrm{~mm}\right)$. A perforated carbon/copper net served as support of the particles of $\mathrm{Co}-\mathrm{MoS}_{2} / \mathrm{SBA}-15(6 \mathrm{~nm})$. SAED patterns were obtained using a diaphragm which limited the diffraction to a circular selected area (diameter $250 \mathrm{~nm}$ ). All images were recorded with a Gatan Multiscan CCD camera and evaluated (including Fourier analyses) with the program Digital Micrograph 3.6.1 (Gatan). EDS analyses were performed in the nanoprobe mode of CM30ST with a Si/Li detector (Noran, Vantage System).

Hydrodesulfurization of dibenzothiophene (DBT) was carried out in a Parr model 4522 high-pressure batch reactor. $1.0 \mathrm{~g}$ of the catalyst and $150 \mathrm{~mL}$ of the freshly prepared solution of DBT in decaline $(5 \% \mathrm{wt} / \mathrm{wt}$., $\left.[\mathrm{DBT}]_{0}=0.2388 \mathrm{~mol} / \mathrm{L}\right)$ were introduced in the reactor. The reactor was then purged and pressurized to $3.4 \mathrm{MPa}$ (490 psi) with hydrogen and then heated up to $623 \mathrm{~K}$ at a rate of $10 \mathrm{~K} / \mathrm{min}$ and continuous stirring of $600 \mathrm{rpm}$. After reaching the working temperature, the products were collected for chromatographic analysis every half an hour to determine the conversion-time dependence during $5 \mathrm{~h}$. After the reaction, the used catalysts were filtered, washed and stored in inert atmosphere. The reaction products were analyzed using a Perkin-Elmer Auto-system chromatograph with a 9 feet long $\times 1 / 8$ inch diameter packed column containing chromosorb W-AW 80/100 mesh 3\% OV-17 (phenyl methyl silicone 50\% phenyl) as a separating phase.

The HDS of DBT occurs by two parallel reaction pathways [18]: (I) direct desulfurization (DDS) via C-S bond cleavage and (II) hydrogenation (HYD). The obtained main products are biphenyl (BP, via DDS), cyclohexylbenzene (CHB, via HYD) and tetrahydrodibenzothiophene (TH-DBT, via HYD). The ratio between HYD and DDS can be approximated in terms of the experimental selectivity according to the following equation:

$\mathrm{HYD} / \mathrm{DDS}=[(\mathrm{PCH})+(\mathrm{TH}-\mathrm{DBT}) /(\mathrm{BP})]$

The rate constant was determined from the DBT conversion as function of time assuming that DBT conversion being a pseudo-zero order reaction [2] by using of following equation:

$X_{\mathrm{DBT}}=(1-\eta \mathrm{DBT}) / \eta \mathrm{DBT}=\left(k / \eta_{\mathrm{DBT}, 0}\right) t$

where $X_{\mathrm{DBT}}$ is the fraction conversion of DBT, $\eta_{D B T}=$ moles of DBT, $k=$ pseudo zero order rate constant, $t=$ time in seconds and $k / \eta_{\mathrm{DBT}, 0}$ is the slope. The mean standard deviation for catalytic measurements was ca. $2.5 \%$.

\section{Results}

\subsection{X-ray Diffraction}

X-ray diffraction patterns of SBA-15 and Co-Mo sulfide catalysts supported on SBA-15 are displayed in Fig. 1. For all samples a prominent diffraction peak at about $1.0^{\circ} 2 \theta$ and two distinct weaker reflections between $1.5^{\circ}$ and $2.0^{\circ}$ $2 \theta$ are observed which are the characteristic reflections (100), (110) and (200) of SBA-15 with space group p6 mm. The occurrence of the characteristic peaks for all catalysts indicates that loading with $\mathrm{Co}$ and Mo species does not deteriorate the primary mesostructure of the SBA-15 support. In addition, the intensity of these diffraction peaks 


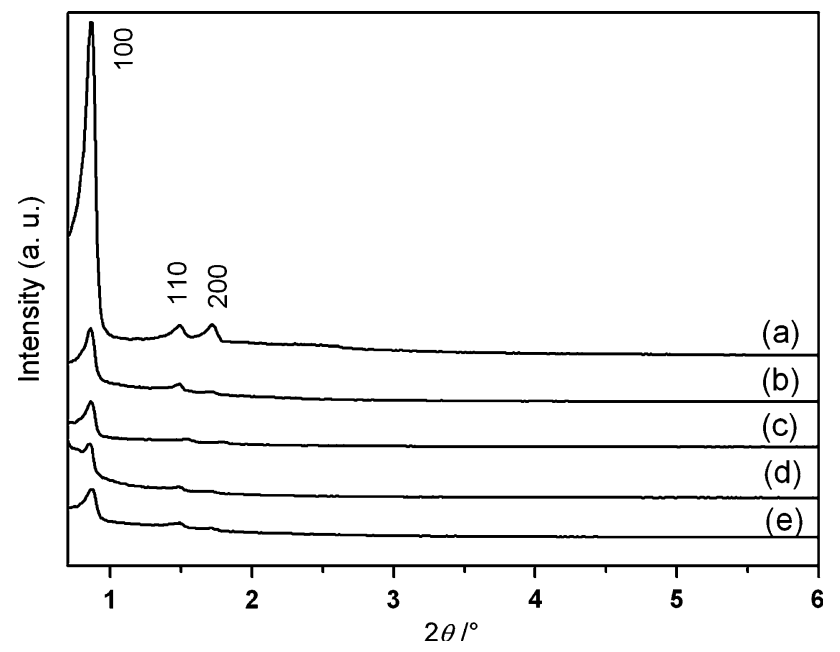

Fig. 1 X-ray diffractometry patterns of a parent SBA-15 $(6 \mathrm{~nm}), \mathbf{b}$ $\mathrm{Co}(1.5) \mathrm{Mo}(11) / \mathrm{SBA}-15(\mathrm{~A})$, c $\mathrm{Co}(2.5) \mathrm{Mo}(20) / \mathrm{SBA}-15(\mathrm{~B})$, d $\mathrm{Co}(4.0)$ $\mathrm{Mo}(20) / \mathrm{SBA}-15(\mathrm{C})$, e Co(1.5)Mo(11)/SBA-15(C)

(Fig. 1) decreases after the Co and Mo incorporation. The reduction of the intensity can be explained by the strong absorption of X-rays by $\mathrm{Mo}(\mathrm{Co})$ and/or a partial loss of the high order of the mesostructure. The same phenomenon was observed in previous studies $[9,12,19]$.

In Fig. 2 the XRD patterns of Co-Mo sulfide catalysts supported on SBA- 15 are displayed for the $2 \theta$ range from $7^{\circ}$ to $75^{\circ}$. The broad modulation at about $22^{\circ} 2 \theta$ is caused by the amorphous silica. For all catalysts typical diffraction patterns of poorly crystalline $2 \mathrm{H}-\mathrm{MoS}_{2}$ with the characteristic reflections at $14.4,33,40$ and $58^{\circ} 2 \theta$ are observed. The asymmetric shape on the low angle side of the reflections at $33^{\circ}, 40^{\circ}$ and $58^{\circ} 2 \theta$ is a typical feature of layered materials

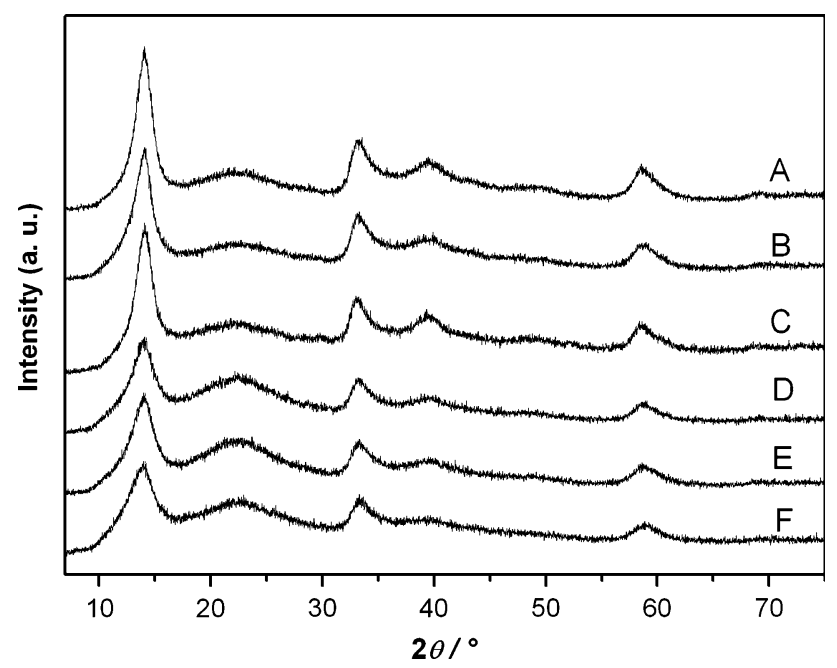

Fig. 2 Wide-angle XRD patterns of a $\mathrm{Co}(2.5) \mathrm{Mo}(20) / \mathrm{SBA}-15(\mathrm{~A}), \mathbf{b}$ $\mathrm{Co}(2.5) \mathrm{Mo}(20) / \mathrm{SBA}-15(\mathrm{~B})$, c $\mathrm{Co}(4.0) \mathrm{Mo}(20) / \mathrm{SBA}-15(\mathrm{C})$, d Co(1.5) $\mathrm{Mo}(11) / \mathrm{SBA}-15(\mathrm{C})$, e $\mathrm{Co}(2.5) \mathrm{Mo}(11) / \mathrm{SBA}-15(\mathrm{~A}), \mathbf{f} \mathrm{Co}(2.5) \mathrm{Mo}(11) /$ SBA-15(B) with a partial turbostratic disorder [12, 20]. The average $\mathrm{MoS}_{2}$ particle size can be determined from the peak width (full width at half maximum, FWHM) and the reflection position using the Scherrer formula, $d=0.941 \lambda / B \cos \theta_{\mathrm{B}}$, where $d$ is the mean diameter of the particle, $\lambda$ is the wavelength of the $\mathrm{Cu} \mathrm{K} \mathrm{K}_{\alpha 1}$ line, $\theta_{\mathrm{B}}$ is the angle between the incident beam and the reflecting lattice plane and $B$ is the width of the diffraction peak. Using the (002) reflection, the mean $\mathrm{MoS}_{2}$ particle size is estimated to be $3-4 \mathrm{~nm}$ (Table 1), which corresponds to an average of five to six stacked $\mathrm{MoS}_{2}$ layers along the $c$-axis assuming $0.613 \mathrm{~nm}$ for the $\mathrm{MoS}_{2}$ slabs. The size of the $\mathrm{MoS}_{2}$ nanocrystals is smaller than the pore diameter of the SBA-15 material (ca. $6 \mathrm{~nm}$ ) and it can be assumed that the $\mathrm{MoS}_{2}$ particles are located inside the channels of SBA-15. From the data compiled in Table 1 it is obvious that the size of the $\mathrm{MoS}_{2}$ nanocrystals increases with increasing Mo loading. Interestingly, the catalysts derived from the TMATM precursor present somewhat smaller $\mathrm{MoS}_{2}$ particles compared to the catalysts obtained from ATM. Furthermore, the introduction of Co by post-impregnation seems to have minor influence onto the crystallinity of the $\mathrm{MoS}_{2}$ particles (Fig. 2d). Independent of the Co content no reflections corresponding to cobalt sulfides can be detected (Fig. 2), indicating that Co is very well-dispersed on the catalytically active material.

\subsection{Nitrogen Physisorption}

The $\mathrm{N}_{2}$ adsorption-desorption isotherms $(77 \mathrm{~K})$ of the materials are illustrated in Fig. 3. For all $\mathrm{Co}-\mathrm{MoS}_{2} / \mathrm{SBA}-15$ catalysts a type IV isotherm is observed, which is the typical feature for mesoporous materials, evidencing that the incorporation of Co and Mo species does not destroy the mesoporous structure of SBA-15. Particularly, the loading of Co-Mo sulfides derived from TMATM led to a typical inkbottle shape [5] [Fig. 3c, Co(1.5)Mo(11)/SBA-15(B)] caused by small Co-Mo sulfide particles settling within the mesopores. The mean pore diameter is shifted marginally toward higher values after introduction of $\mathrm{Mo}$ and $\mathrm{Co}$ in SBA-15 suggesting minor changes occurring after the introduction of Mo and Co. A similar phenomenon was described in previous reports $[8,12]$. The specific surface areas of SBA-15 and the $\mathrm{Co}-\mathrm{MoS}_{2} / \mathrm{SBA}-15$ catalysts are summarized in Table 1. The normalized surface areas were calculated considering dilution effects of the metal loading as described in [21]. The impregnation of the SBA-15 pores with Co-Mo sulfides results in a decrease of surface areas which is caused by a partial pore blocking by the $\mathrm{Co}-\mathrm{MoS}_{2}$ phases, because the formation of Mo and Co sulfides inside the channels of the SBA-15 material should not significantly affect the surface areas due to their high density. A more pronounced blocking of the pores is observed for the catalysts prepared with TMATM, which exhibit the lowest normalized surface areas (Table 1). Moreover, comparing 
Table 1 Specific surface areas, normalized surface areas of SBA-15 support and SBA-15 supported Co-Mo sulfide catalysts and the mean $\mathrm{MoS}_{2}$ crystal size supported on SBA-15

Normalized $(S)=S_{(\mathrm{Co}-\mathrm{Mo})} /$ [ $\left.\left(1-w_{\mathrm{f}}\right) S_{\mathrm{SBA}-15}\right]$, where $S$ is the specific surface area, $w_{\mathrm{f}}$ is the weight fraction of CoMo sulfides

Fig. 3 Nitrogen adsorption/ desorption isotherms (A) and pore size distribution of (a) parent SBA-15, (b) $\mathrm{Co}(1.5) \mathrm{Mo}(11) / \mathrm{SBA}-15(\mathrm{~A}),(\mathbf{c})$ $\mathrm{Co}(2.5) \mathrm{Mo}(20) / \mathrm{SBA}-15$ (A) and (d) $\mathrm{Co}(1.5) \mathrm{Mo}(11) / \mathrm{SBA}-15(\mathrm{~B})$

\begin{tabular}{|c|c|c|c|c|c|}
\hline \multirow[t]{2}{*}{ Catalysts } & \multirow{2}{*}{$\begin{array}{l}\text { Mo } \\
\text { (wt. \%) }\end{array}$} & \multirow{2}{*}{$\begin{array}{l}\text { Co } \\
\text { (wt. \%) }\end{array}$} & \multicolumn{2}{|c|}{ BET surface area $\left(\mathrm{m}^{2} \mathrm{~g}^{-1}\right)$} & \multirow{2}{*}{$\begin{array}{l}\mathrm{MoS}_{2} \text { mean } \\
\text { crystallite } \\
\text { size }(\mathrm{nm})\end{array}$} \\
\hline & & & & Normalized & \\
\hline SBA-15 & 0 & 0 & 742.2 & 1 & - \\
\hline $\mathrm{Co}(1.5) \mathrm{Mo}(11) / \mathrm{SBA}-15(\mathrm{~A})$ & 11 & 1.5 & 303.6 & 0.52 & 3.4 \\
\hline $\mathrm{Co}(2.5) \mathrm{Mo}(20) / \mathrm{SBA}-15(\mathrm{~A})$ & 20 & 2.5 & 253.7 & 0.55 & 4.3 \\
\hline $\mathrm{Co}(1.5) \mathrm{Mo}(11) / \mathrm{SBA}-15(\mathrm{~B})$ & 11 & 1.5 & 227.2 & 0.39 & 3.0 \\
\hline $\mathrm{Co}(2.5) \mathrm{Mo}(20) / \mathrm{SBA}-15(\mathrm{~B})$ & 20 & 2.5 & 182.3 & 0.41 & 3.6 \\
\hline $\mathrm{Co}(1.5) \mathrm{Mo}(11) / \mathrm{SBA}-15(\mathrm{C})$ & 11 & 1.5 & 316.4 & 0.53 & 3.2 \\
\hline $\mathrm{Co}(4) \mathrm{Mo}(20) / \mathrm{SBA}-15(\mathrm{C})$ & 20 & 4 & 248.4 & 0.55 & 4.4 \\
\hline CoMo(ATM & 67 & 8 & - & - & 3.0 \\
\hline CoMo(TMATM) & 67 & 8 & - & - & 2.1 \\
\hline
\end{tabular}
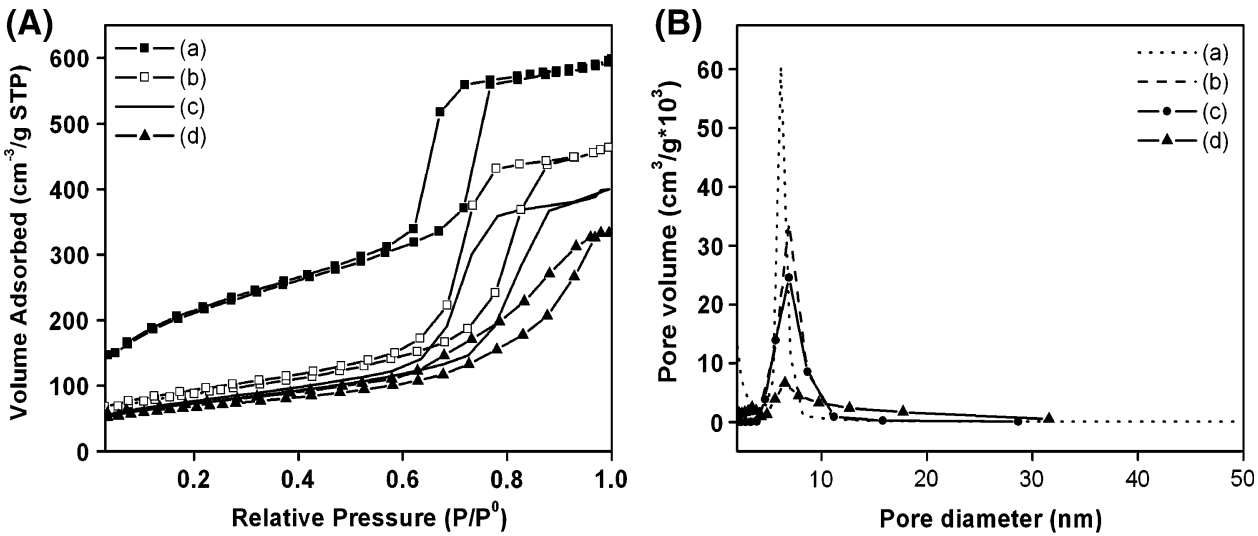

the results obtained for $\mathrm{Co}(1.5) \mathrm{Mo}(11) / \mathrm{SBA}-15(\mathrm{~A})$ and $\mathrm{Co}(1.5) \mathrm{Mo}(11) / \mathrm{SBA}-15(\mathrm{C})$ it is obvious that the sequence of the impregnation steps has only a small influence onto the alteration of the surface area. An increase of the Co promoter concentration from $2.5 \mathrm{wt} \%(\mathrm{Co}(2.5) \mathrm{Mo}(20) / \mathrm{SBA}-15(\mathrm{~A}))$ to $4 \mathrm{wt} \%(\mathrm{Co}(4) \mathrm{Mo}(20) / \mathrm{SBA}-15$ (C)) yields no significant change of the surface area (Table 1).

\subsection{Transmission Electron Microscopy}

The hexagonal mesostructure of the SBA-15 support is preserved after all impregnation procedures, however, the samples prepared from ATM and TMATM exhibit distinct real structure phenomena. Both $\mathrm{Co}(4) \mathrm{Mo}(20) / \mathrm{SBA}-15(\mathrm{~A})$ and $\mathrm{Co}(2.5) \mathrm{Mo}(20) / \mathrm{SBA}-15(\mathrm{~A})$ obtained from ATM are characterized by a high density of slabs with a low aspect ratio dispersed on the SBA-15 support (Fig. 4). EDS analyses indicate the presence of the slabs by strong peaks of Mo-K and S-K (coinciding with Mo-L) and weak intensity assigned to $\mathrm{Co}-\mathrm{K}$. The ratio of Mo:S was calculated to be close to 0.5 in many cases. SAED patterns recorded on the SBA-15 particles show broad diffuse rings with the diameters in good agreement to calculated values based on the metrics of $\mathrm{Co}-\mathrm{MoS}_{2}$ slabs. Bright-field images of these selected areas display a high density of $\mathrm{Co}-$
$\mathrm{MoS}_{2}$ slabs with a typical thickness of ca. $4 \mathrm{~nm}$ along the $c$-axis of a $\mathrm{MoS}_{2}$-type structure. As evidenced by HRTEM these slabs are built from five to eight consecutive (001) layers. With respect to their length, the $\mathrm{MoS}_{2}$ slabs can be separated in two groups, furthermore a characteristic spatial distribution of short and long slabs is observed (Fig. 4).

(1) Very long slabs which cover the edges of the SBA15 particles (see arrow in Fig. 4a). The long slabs are frequently bent and exhibit prominent stacking faults. (2) Short slabs with an estimated aspect ratio between 1.5 and 3 . They are usually observed apart from the edges of the support, see Fig. 4a (right) and b. HRTEM micrographs (see Fig. 4c) indicate a high density of rotationally disordered slabs with a preferred orientation along the zone axes $[u v 0]$. Like electron diffraction patterns, the FFTs of the micrographs contain the high-intensity (002) peak of the $\mathrm{Co}-\mathrm{MoS}_{2}$ phases, see intensity on circle 1 in Fig. $4 \mathrm{c}$, right. For the Co-rich sample Co(4)Mo(20)/SBA-15(A) the slabs do not exhibit a higher Co content. The combined approach of electron diffraction and EDS analyses demonstrate that the Co excess covers wide areas of the SBA-15 support.

The distribution of short and long slabs was not observed for the samples prepared from TMATM, particularly not for the sample $\mathrm{Co}(2.5) \mathrm{Mo}(20) / \mathrm{SBA}-15(\mathrm{~B})$. As a rule, areas like the one presented in Fig. 5a with a high density of short slabs 
Fig. 4 Electron microscopy performed on sample $\mathrm{Co}(2.5) \mathrm{Mo}(20) / \mathrm{SBA}-15(\mathrm{~A})$. a Bright-field image recorded on the edge of a particle of the SBA15 support. b Bright-field image recorded in the center of the particle of image. c Bright-field image of SBA-15 support covered by a high density of $\mathrm{Co}-\mathrm{MoS}_{2}$ slabs with attached Fourier transform (calculated inside a circular area of image c)
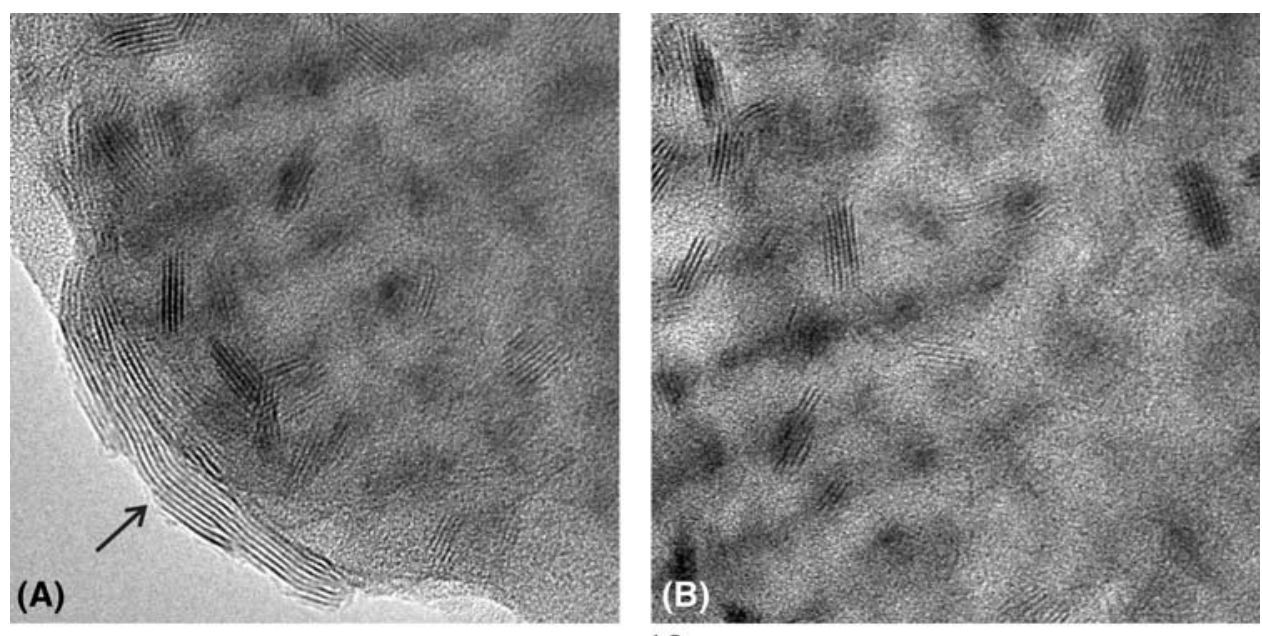

$-10 \mathrm{~nm}$
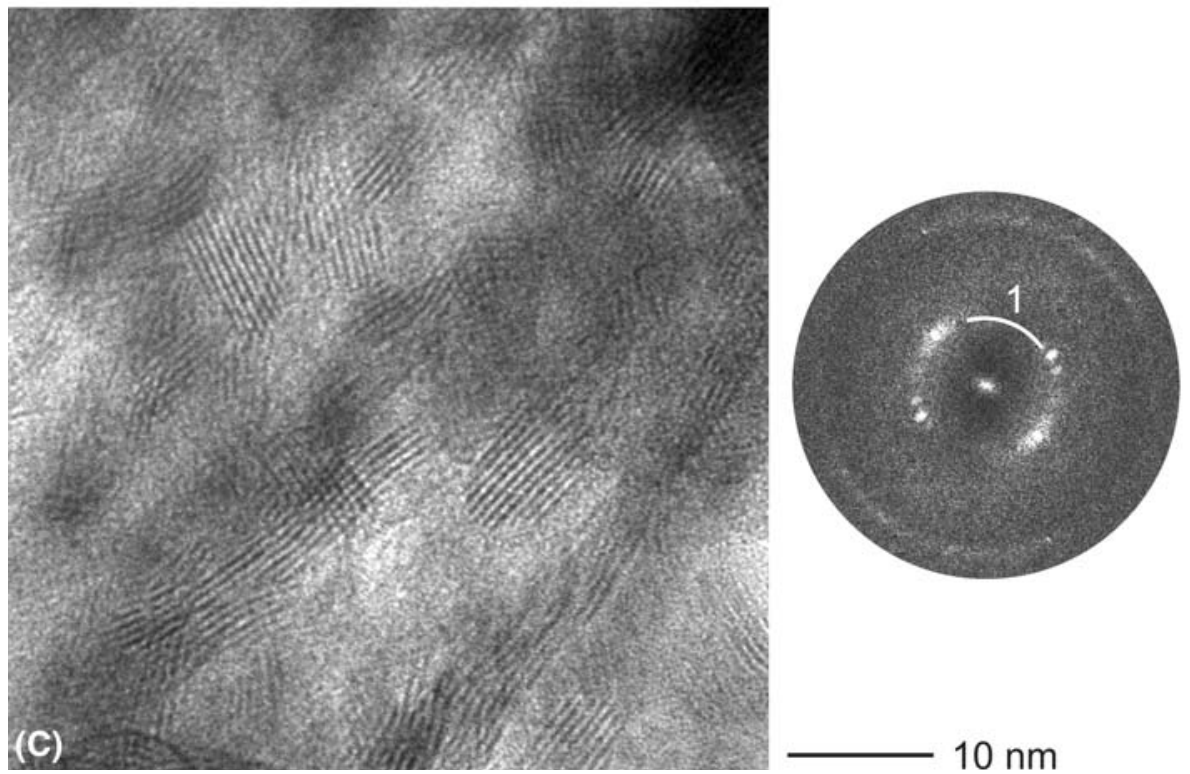

$10 \mathrm{~nm}$ are rarely observed. The Co- $\mathrm{MoS}_{2}$ species preferably form big needle-like aggregates of slabs (Fig. 5b). The single slabs are oriented perpendicular to the needles' axes which coincide with the $c$ axis of the $\mathrm{MoS}_{2}$-type structure. Figure $5 \mathrm{c}$ displays the HRTEM micrograph recorded on the edge of one needle shown in Fig. 5b. The attached SAED pattern was oriented like the Fourier transform of the HRTEM micrograph. The low resolution of the SAED pattern correlates with the low crystalline perfection of the needle perpendicular to $c$ axis. Such phenomenon can be rationalized taking into account the strong bending of adjacent (001) layers which compensates stacking faults.

\subsection{Catalytic Activity and Selectivity}

The results of HDS activity test reactions for $\mathrm{Co}-\mathrm{MoS}_{2} /$ SBA-15 catalysts expressed as conversion of DBT as function of the reaction time are displayed in Fig. 6. The curves show an approximate linear relationship between conversion of DBT and reaction time supporting the assumption of pseudo-zero order kinetics occurring under the experimental conditions. However, deviations from the linear behavior is observed at the end of the reaction for the catalyst with high activity (Fig. 6, Co(4)Mo(20)/SBA15(C)). Such deviations are due to an inhibiting effect of $\mathrm{H}_{2} \mathrm{~S}$ accumulated in the reactor. Table 2 presents the calculated pseudo-zero order rate constants for DBT and the selectivity expressed as the ratio HYD/DDS. The results demonstrate that the impregnation order has a smaller influence onto the activity than the nature of the thiomolybdate precursor. For both supported and unsupported catalysts the materials derived from ATM reveal about $40 \%$ higher activity than the analogous samples achieved from TMATM (Fig. 6). In addition, all catalysts, regardless of the type of the thiomolybdate source, show a high selectivity at DBT conversions of ca. 30\% (HYD/ 
Fig. 5 Electron microscopy performed on sample $\mathrm{Co}(2.5) \mathrm{Mo}(20) / \mathrm{SBA}-15$ (B). a Bright-field image of $\mathrm{Co}-\mathrm{MoS}_{2}$ slabs on SBA-15 support. b Thick needle of $\mathrm{MoS}_{2}$ (direction of growth highlighted). c HRTEM micrograph recorded at the edge of the needle with attached SAED pattern

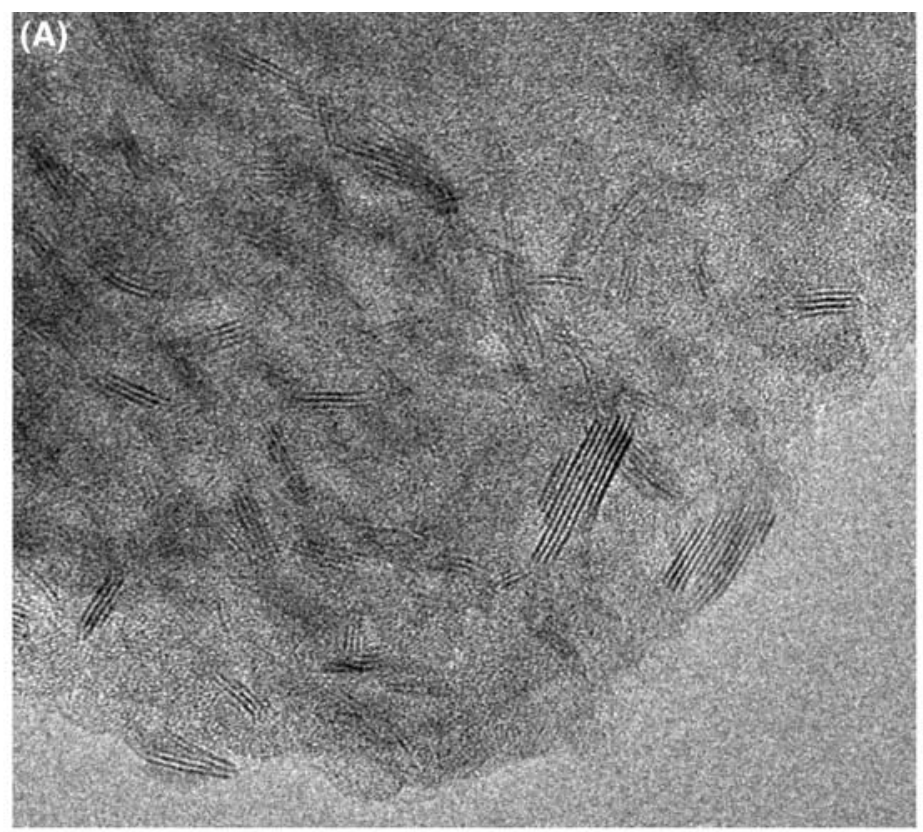

$10 \mathrm{~nm}$

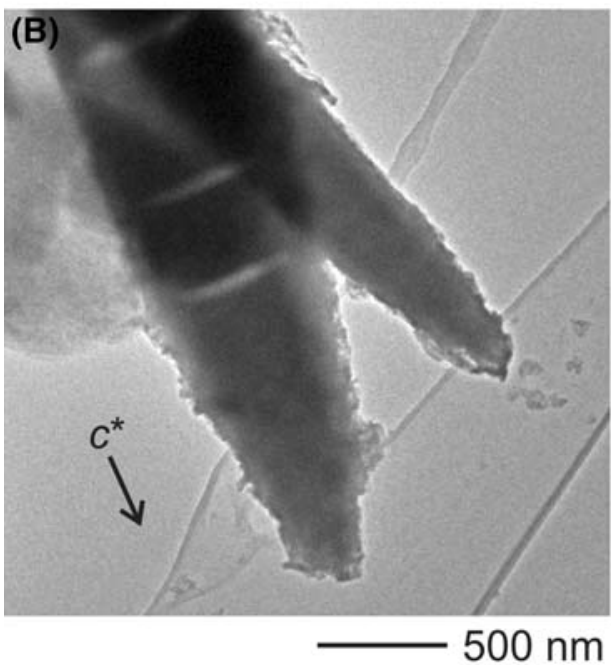

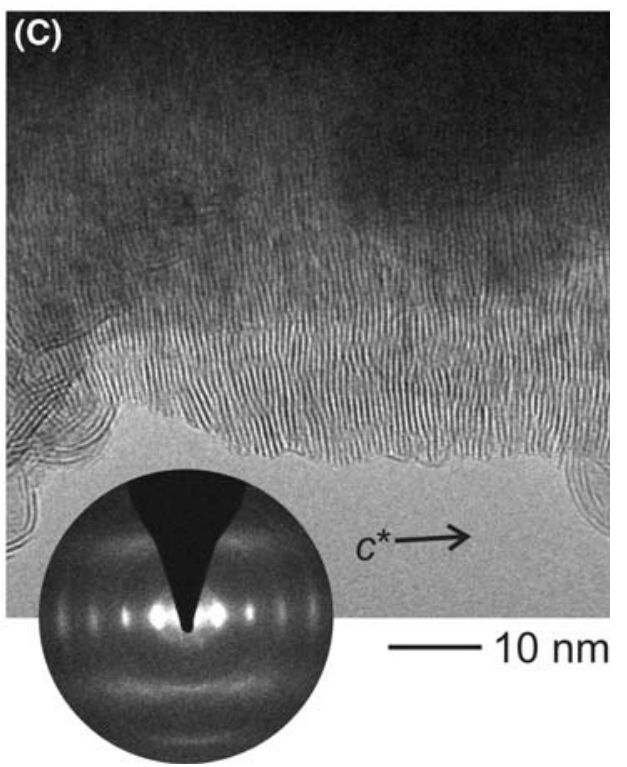

DDS 0.2), being in good agreement with the results published in a previous study [12]. The total DBT conversions after $5 \mathrm{~h}$ reaction time for all catalysts are displayed in Fig. 7 together with data taken from [12, 22] for comparison. Analyzing the results it is obvious that an increase of Mo and Co loading leads to an increase of the activity, and the catalyst with the highest Co content is the most active in the HDS reaction. With the exception of $\mathrm{Co}(1.5) \mathrm{Mo}(20) / \mathrm{SBA}-15(\mathrm{~B})$, all SBA-15 supported catalysts exhibit higher catalytic activity than the commercial $\mathrm{CoMo} / \gamma-\mathrm{Al}_{2} \mathrm{O}_{3}$ sample. The unsupported catalyst CoMo(ATM) has a higher HDS performance compared to the catalyst prepared from TMATM, indicating that the Mo source seems to be important also for unsupported catalysts.

\section{Discussion}

The thermal decomposition of molybdenum thiosalts was applied as an alternative method for the preparation of HDS catalysts. Using Mo precursors containing alkyl groups instead of the small ammonium ion yield a new type of sulfide materials during the thermal decomposition which could be called "amorphous mesoporous sulfide" catalysts with a remarkable increase of the HDS catalytic 


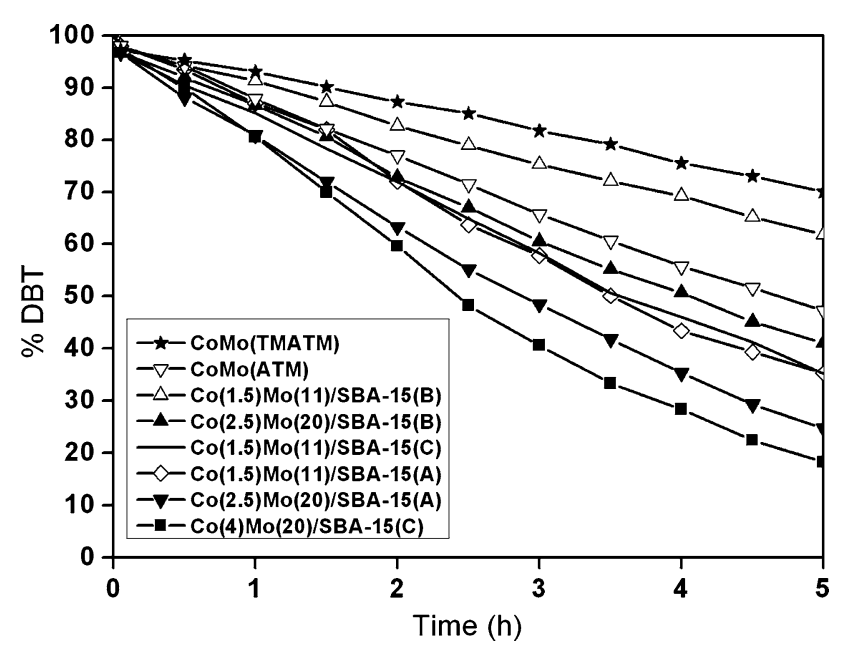

Fig. 6 Dibenzothiophene conversion as function of reaction time for the $\mathrm{Co}-\mathrm{MoS}_{2} / \mathrm{SBA}-15$ catalysts

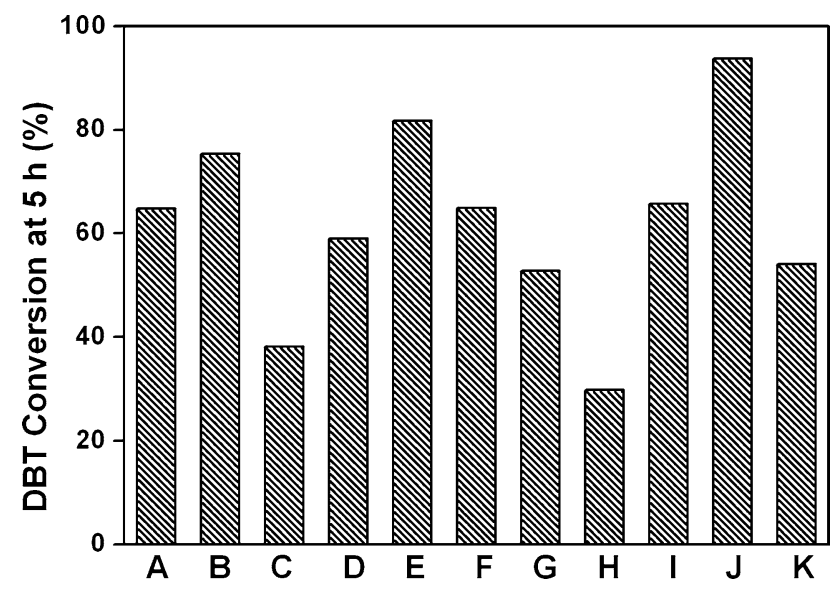

Fig. 7 Total DBT conversion at $5 \mathrm{~h}$ of reaction time for the samples a $\mathrm{Co}(1.5) \mathrm{Mo}(11) / \mathrm{SBA}-15(\mathrm{~A})$; b $\mathrm{Co}(2.5) \mathrm{Mo}(20) / \mathrm{SBA}-15(\mathrm{~A})$; c $\mathrm{Co}$ (1.5) Mo(11)/SBA-15(B); d $\mathrm{Co}(2.5) \mathrm{Mo}(20) / \mathrm{SBA}-15(\mathrm{~B}) ; \quad$ e $\mathrm{Co}(4)$ $\mathrm{Mo}(20) / \mathrm{SBA}-15(\mathrm{C})$; f $\mathrm{Co}(1.5) \mathrm{Mo}(11) / \mathrm{SBA}-15(\mathrm{C})$; g CoMo(ATM); h CoMo(TMATM); i Co(2)Mo(10)/SBA-15 from reference [12]; j $\mathrm{Co}(2) \mathrm{Mo}(20) / \mathrm{SBA}-15$ from reference [12]; $\mathbf{k} \mathrm{CoMo} / \mathrm{Al}_{2} \mathrm{O}_{3}$ from reference [22]

activity [20, 23, 24]. Recently, the decomposition of ATM was successfully applied for the preparation of catalysts supported on SBA-15 [12]. In the present study the catalytic active Co-Mo sulfides supported on SBA-15 were obtained using S containing Mo and Co sources ATM, TMATM, and CoDMTC, avoiding any step where an oxidic compound must transformed to a sulfide. In agreement with previous results [12], the catalysts derived from ATM exhibit interesting high activity at high metal loading despite the relatively pronounced $\mathrm{MoS}_{2}$ stacking (compare Fig. 4). Such a good HDS performance indicates the presence of a large amount of catalytic active sites, "vacancies" or co-ordinatively unsaturated sites ("CUS"). Nowadays, the most widely accepted model for the structure of promoted HDS catalysts is the model developed by Topsøe [25]. It was reported that Co substitutes Mo atoms at the $\mathrm{S}$ edge creating a tetrahedral environment of Co (Co-Mo-S edge) [26], and it was shown for CoMoS phases that a $\mathrm{S}$ atom having bonds to Mo and Co is less strong bound than a $\mathrm{S}$ atom with bonds to two Mo atoms and therefore such a $\mathrm{S}$ atoms can be removed easily creating a vacancy [25]. The presence of Co located on the $\mathrm{MoS}_{2}$ slabs confirmed by EDS analyses (see HRTEM) indicates the formation of the CoMoS phase. On the other hand it may be possible that more CUS are generated during the thermal decomposition of the ATM precursor in a $\mathrm{H}_{2} / \mathrm{N}_{2}$ atmosphere. A high catalytic activity of $\mathrm{WS}_{2}$ catalysts prepared by decomposition of ammonium tetrathiotungstate in $\mathrm{H}_{2}$ was reported by Wilkinson et al. to be attributed probably to the presence of more anion vacancies (or more CUS) [27]. However, an improvement of the HDS performance could not be observed compared with the catalysts which were studied by us very recently containing crystalline $\mathrm{Co}_{9} \mathrm{~S}_{8}$ [12]. This finding is somewhat surprising because in the X-ray powder patterns of the present catalysts no hints for crystalline Co sulfides are found (Fig. 2). But it was also reported in the literature that segregated $\mathrm{Co}_{9} \mathrm{~S}_{8}$ might play a distinct catalytic role according to the "Remote Control" concept [28]. This would explain that the present catalysts exhibit a HDS activity comparable to catalysts containing crystalline Co sulfide [12]. But the relatively high HDS activity is in agreement with the results of the study of Eijsbouts et al. [29], who investigated the catalytic activity of unsupported liquid-phasesulfided Type 2 commercial ULSD catalysts. They pointed out that $\mathrm{MoS}_{2}$ stacking is not a prerequisite for a good performance and also not a sign of deactivation or lower activity.

The decomposition of TMATM leads to a somewhat lower stacking number of $\mathrm{MoS}_{2}$ slabs compared to that of ATM (Table 1, Fig. 2). But in addition, the TMATM precursor causes a more pronounced pore blocking (Table 1, Fig. 3) and this effect may be of importance for the catalytic activity. A partial blocking of the pore entrance may lead to a decrease in accessibility of the reactants to the active sites [30, 31]. Moreover, the unsupported CoMo catalyst derived from ATM presents a higher HDS activity than the material prepared from TMATM (Figs. 6, 7 histograms $\mathrm{G}$ and $\mathrm{H}$ ). To explain this result one should therefore consider the different behavior of the two precursors during the thermal decomposition reaction. It was suggested that intermediately formed $\mathrm{MoS}_{3}$ plays an important role in the formation of the active catalyst supported on so-called activated-carbon [32]. It is well-established that the thermal decomposition of ATM proceeds via intermediately formed $\mathrm{MoS}_{3}$, whereas TMATM is decomposed directly to a carbon containing 
Table 2 Initial rate constants $(k)$ and selectivity HYD/DDS (estimated at a DBT conversion of ca. $30 \%$ ) of the $\mathrm{Co}-\mathrm{MoS}_{2} / \mathrm{SBA}-15$ catalysts during the HDS reaction of DBT

\begin{tabular}{lll}
\hline Catalysts & $\begin{array}{l}k \text { (specific) } \\
\left(1 \times 10^{-7} \mathrm{~mol} / \mathrm{g} \mathrm{s}\right)\end{array}$ & $\begin{array}{l}\text { HYD/ } \\
\text { DDS ratio }\end{array}$ \\
\hline $\mathrm{Co}(1.5) \mathrm{Mo}(11) / \mathrm{SBA}-15(\mathrm{~A})$ & 13.9 & 0.24 \\
$\mathrm{Co}(2.5) \mathrm{Mo}(20) / \mathrm{SBA}-15(\mathrm{~A})$ & 15.2 & 0.19 \\
$\mathrm{Co}(1.5) \mathrm{Mo}(11) / \mathrm{SBA}-15(\mathrm{~B})$ & 7.3 & 0.23 \\
$\mathrm{Co}(2.5) \mathrm{Mo}(20) / \mathrm{SBA}-15(\mathrm{~B})$ & 11.8 & 0.21 \\
$\mathrm{Co}(1.5) \mathrm{Mo}(11) / \mathrm{SBA}-15(\mathrm{C})$ & 13.6 & 0.21 \\
$\mathrm{Co}(4) \mathrm{Mo}(20) / \mathrm{SBA}-15(\mathrm{C})$ & 19.2 & 0.18 \\
$\mathrm{CoMo}(\mathrm{ATM})$ & 11.0 & 0.41 \\
$\mathrm{CoMo(TMATM})$ & 5.7 & 0.29 \\
\hline
\end{tabular}

Mo sulfide [16]. In the case of $\mathrm{Co}-\mathrm{MoS}_{2} / \mathrm{SBA}-15$ (A), CoDMTC is decomposed simultaneously during the generation of $\mathrm{MoS}_{2}$ from ATM and Co-MoS $/$ SBA-15(C) was prepared by post-impregnation of (Co) $\mathrm{MoS}_{2} / \mathrm{SBA}-15$ with CoDMTC. Both synthesis methods yield catalysts with a comparable surface area. Moreover, at the same Mo and Co loading, the two catalysts present a similar HDS activity (Table 2, Fig. 6 and 7). This result indicates that the Co atoms are able to migrate directly to the edges of $\mathrm{MoS}_{2}$ to form the active CoMoS phase in both cases. The intermediate $\mathrm{MoS}_{3}$ seems to be not a prerequisite for the generation of active $\mathrm{CoMoS}$ phases under the actual synthesis conditions.

On the other hand, the Co promoting effect might be hindered strongly by carbon entities formed during the decomposition of a tetraalkylammonium thiomolybdate precursor [33], e.g. the cobalt synergetic effect could be completely suppressed like for the ex situ activated Co promoted catalyst using TMATM as Mo source [33]. Unfortunately, the suppression of such a synergetic effect cannot be evaluated by the HRTEM imaging technique. But, the precursor type has shown a strong influence on the $\mathrm{MoS}_{2}$ morphology detected in HRTEM micrographs. High density of short slabs appears on the catalysts derived from ATM, whereas for the catalysts using TMATM the CoMo species preferably form big needle-like aggregates of slabs with a low crystalline perfection perpendicular to the $c$ axis (compare Figs. 4, 5). The distinct $\mathrm{MoS}_{2}$ morphologies should be mainly responsible for the observed different HDS performance. In summary, it can be concluded that the efficiency of the decomposition process to generate good catalysts depends on the type of the precursor and the chosen conditions [34].

Increasing HDS activity with increasing Mo loading is visible when the same precursor is employed (Table 2). It is well-known that the optimal atomic $\mathrm{Co} / \mathrm{Mo}$ ratio for $\gamma-\mathrm{Al}_{2} \mathrm{O}_{3}$ supported HDS catalysts is 0.4 [35]. Consequently, the cobalt loading of one of the present catalysts
$\mathrm{Co}(2.5) \mathrm{Mo}(20) / \mathrm{SBA}-15$ (A) was increased to this ratio to monitor the change of the HDS activity as function of $\mathrm{Co}$ content. Increasing the Co concentration by post-impregnation leads apparently to an increase in HDS activity [see $\mathrm{Co}(4) \mathrm{Mo}(20) / \mathrm{SBA}-15(\mathrm{C})]$. For this Co-rich sample, the absence of reflections of crystalline Co sulfides in the $\mathrm{X}$-ray powder pattern (Fig. 2) indicates that the usage of CoDMTC retards crystallization of such $\mathrm{CoS}_{x}$ crystallites. Interestingly, the HRTEM/EDS investigation of this sample shows that the Co content is not larger than for $\mathrm{Co}(2.5) \mathrm{Mo}(20) / \mathrm{SBA}-15(\mathrm{~B})$. The excess $\mathrm{CoS}_{x}$ species are finely dispersed over the large surface area of SBA-15. The result of the HDS test suggests that the amorphous cobalt sulfide may be responsible for the enhanced HDS activity. But at this stage one can only speculate about the effect of the $\operatorname{CoS}_{x}$ particles onto the enhancement of the HDS activity. One possibility I the so-called spill-over effect but one can also imagine that the finely dispersed $\operatorname{CoS}_{x}$ itself acts as an active catalytic material.

The HYD/DDS ratio of $\mathrm{Co}-\mathrm{MoS}_{2} / \mathrm{SBA}-15$ catalysts prepared from different $\mathrm{S}$ containing starting materials and different synthesis methods scatters around 0.2 [exception: CoMo(ATM), Table 2], and these ratios are in accordance with the results from our previous study [12]. Multilayered $\mathrm{WS}_{2}$ slabs have been confirmed by Vradman and Landau to facilitate $\pi$-complexation of the aromatic ring with respect to single-layered or thin slabs [36], and consequently result in higher HYD activity. Opposite to that, the present catalysts with multilayered $\mathrm{MoS}_{2}$ slabs shows a strong preference for the DDS pathway which may be correlated mainly to the promoting effect of Co. It has been proposed that the promoting effect of $\mathrm{Co}$ is due to an increased mobility of $\mathrm{S}$ atoms in the Co-MoS phase where the strength of the Mo-S bond is considered to be weakened. But the pronounced selectivity for the DDS route could be also related to the presence of a large amount of CUS (Lewis acid sites) in our supported catalysts. Furthermore, the results of different studies suggest that hydrogenolysis and HYD reactions occur on separate sites, i.e., on Lewis acid sites (vacancies) and Brønsted acid sites [22].

\section{Conclusions}

In the present study an all sulfur route for the preparation of Co promoted $\mathrm{MoS}_{2}$ catalysts supported on SBA-15 are presented. This method avoids the treatment of the materials in a poisonous $\mathrm{H}_{2} \mathrm{~S}$ atmosphere. The catalysts obtained from ATM exhibit higher catalytic activity compared to a $\mathrm{CoMo} / \gamma-\mathrm{Al}_{2} \mathrm{O}_{3}$ catalyst despite of the pronounced $\mathrm{MoS}_{2}$ stacking. An explanation for the observed high HDS activity and selectivity for the DDS pathway is the co-operative or synergistic effect of a $\mathrm{Co}-$ 
MoS phase as well as large amount of vacancies (CUS). The synergetic effect of Co depends on the nature of the thiosalt precursor material. In the case of catalysts derived from TMATM, large needle-like aggregates of $\mathrm{Co}-\mathrm{MoS}_{2}$ slabs are formed and a pronounced pore blocking effect is observed. These two properties may be the important factors for the lower HDS activities compared to the catalysts obtained from ATM. In addition, our study highlights that the intermediate $\mathrm{MoS}_{3}$ is not a prerequisite for the generation of catalytic active Co-MoS phases. A more active catalyst was obtained by increasing the Co content through post-impregnation method due to the positive contribution of amorphous cobalt sulfide to the catalytic performance. In further studies the new synthetic approach is tested with different supports to monitor the influence of the support material onto the catalytic activity and selectivity.

Acknowledgments The financial support of the Deutsche Forschungsgemeinschaft (DFG) and of the State of Schleswig-Holstein is greatly acknowledged.

\section{References}

1. Hagenbach G, Courty P, Delmon B (1973) J Catal 31:264

2. Candia R, Clausen BS, TopsØe H (1982) J Catal 77:564

3. Zdrazil M (1988) Catal Today 3:269

4. Zhao D, Feng J, Huo Q, Melosh N, Fredrickson GH, Chmelka BF, Stucky GD (1998) Science 279:548

5. Vradman L, Landau MV, Herskowitz M, Ezersky V, Talianker M, Nikitenko S, Koltypin Y, Gedanken A (2003) J Catal 213:163

6. Dhar GM, Kumaran GM, Kumar M, Rawat KS, Sharma LD, Raju BD, Rao KSR (2005) Catal Today 99:309

7. Klimova T, Lizama L, Amezcua JC, Roquero P, Terrés E, Navarrete J, Domínguez JM (2004) Catal Today 98:141

8. Kumaran GM, Garg S, Soni K, Kumar M, Sharma LD, Dhar GM, Rao KSR (2006) Appl Catal A Gen 305:123

9. Gutiérrez OY, Fuentes GA, Salcedo C, Klimova T (2006) Catal Today 116:485

10. Gutiérrez OY, Valencia D, Fuentes GA, Klimova T (2007) J Catal 249:138

11. Breysse M, Afanasiev P, Geantet C, Vrinat M (2003) Catal Today $86: 5$
12. Huang Z-D, Bensch W, Kienle L, Fuentes S, Alonso G, Ornelas C (2008) Catal Lett 122:57

13. Sundaramurthy V, Dalai AK, Adjaye J (2005) Catal Lett 102:299

14. Coulier L, Kishan G, van Veen JAR, Niemantsverdriet JW (2002) J Phys Chem B 106:5897

15. Rana MS, Ramírez J, Gutiérrez-Alejandre A, Ancheyta J, Cedeňo L, Maity SK (2007) J Catal 246:100

16. Poisot M, Bensch W, Fuentes S, Alonso G (2006) Thermochim Acta 444:35

17. Cambi L, Cagnasso A, Tanara A (1931) Atti Linc 13:404

18. Whitehurst DD, Isoda T, Mochida I (1998) Adv Catal 42:345

19. Huang Z-D, Bensch W, Sigle W, van Aken PA, Kienle L, Vitova T, Modrow H, Ressler T (2008) J Mater Sci 43:244

20. Poisot M, Bensch W, Fuentes S, Ornelas C, Alonso G (2007) Catal Lett 117:2007

21. Landau MV, Vradman L, Herskowitz M, Koltypin Y, Gedanken A (2001) J Catal 201:22

22. Nava R, Ortega RA, Alonso G, Ornelas C, Pawelec B, Fierro JLG (2007) Catal Today 127:70

23. Alonso G, Berhault G, Aguilar A, Collins V, Ornelas C, Fuentes S, Chianelli RR (2002) J Catal 208:359

24. Nava H, Ornelas C, Aguilar A, Berhault G, Fuentes S, Alonso G (2003) Catal Lett 86:257

25. Topsoe H, Clausen BS (1984) Catal Rev Sci Eng 26:395

26. Lauritsen JV, Kibsgaard J, Olesen GH, Moses PG, Hinnemann B, Helveg S, NØrskov JK, Clausen BS, TopsØe H, Lægsgaard E, Besenbacher F (2007) J Catal 249:218

27. Wilkinson K, Merchan MD, Vasudevan PT (1997) J Catal $171: 325$

28. Karroua M, Matralis H, Grange P, Delmon B (1993) J Catal 139:371

29. Eijsbouts S, van den Oetelaar LCA, van Puijenbroek RR (2005) J Catal 229:352

30. Furimsky E, Massoth FE (1993) Catal Today 17:535

31. Absihalabi M, Stanislaus A, Trimm DL (1991) Appl Catal 72:193

32. Brito JL, Severino F, Delgado NN, Laine (1998) Appl Catal A Gen 173:193

33. Alvarez L, Espino J, Ornelas C, Rico JL, Cortez MT, Berhault G, Alonso G (2004) J Mol Catal Chem 210:105

34. Lauritsen JV, Bollinger MV, Lægsgaard E, Jacobsen KW, Nørskov JK, Clausen BS, Topsøe H, Besenbacher F (2004) J Catal 221:510

35. Al-Zeghayer YS, Sunderland P, Al-Masry W, Al-Mubaddel F, Ibrahim AA, Bhartiya BK, Jibril BY (2005) Appl Catal A Gen 282:163

36. Vradman L, Landau MV (2001) Catal Lett 77:47 